\title{
Cost-effectiveness of raloxifene in the treatment of osteoporosis in Chinese postmenopausal women: impact of medication persistence and adherence
}

\author{
This article was published in the following Dove Press journal: \\ Patient Preference and Adherence \\ 29 March 2016 \\ Number of times this article has been viewed
}

\author{
Mingsheng Chen' \\ Lei $\mathrm{Si}^{2,3}$ \\ Tania M Winzenberg ${ }^{2,4}$ \\ Jieruo $\mathrm{Gu}^{5}$ \\ Qicheng Jiang ${ }^{3}$ \\ Andrew J Palmer ${ }^{2}$ \\ 'School of Health Policy \& \\ Management, Nanjing Medical \\ University, Nanjing, Jiangsu Province, \\ People's Republic of China; ${ }^{2}$ Menzies \\ Institute for Medical Research, \\ University of Tasmania, Hobart, \\ TAS, Australia; ${ }^{3}$ School of Health \\ Administration, Anhui Medical \\ University, Hefei, Anhui, People's \\ Republic of China; ${ }^{4}$ School of \\ Medicine, University of Tasmania, \\ Hobart, TAS, Australia; ${ }^{5}$ Department \\ of Rheumatology, The Third Affiliated \\ Hospital of Sun Yat-Sen University, \\ Guangzhou, People's Republic of \\ China
}

\begin{abstract}
Aims: Raloxifene treatment of osteoporotic fractures is clinically effective, but economic evidence in support of raloxifene reimbursement is lacking in the People's Republic of China. We aimed at evaluating the cost-effectiveness of raloxifene in the treatment of osteoporotic fractures using an osteoporosis health economic model. We also assessed the impact of medication persistence and adherence on clinical outcomes and cost-effectiveness of raloxifene.

Methods: We used a previously developed and validated osteoporosis state-transition microsimulation model to compare treatment with raloxifene with current practices of osteoporotic fracture treatment (conventional treatment) from the health care payer's perspective. A Monte Carlo probabilistic sensitivity analysis with microsimulations was conducted. The impact of medication persistence and adherence on clinical outcomes and the cost-effectiveness of raloxifene was addressed in sensitivity analyses. The simulated patients used in the model's initial state were 65-year-old postmenopausal Chinese women with osteoporosis (but without previous fractures), simulated using a 1-year cycle length until all patients had died. Costs were presented in 2015 US dollars (USD), and costs and effectiveness were discounted at $3 \%$ annually. The willingnessto-pay threshold was set at USD 20,000 per quality-adjusted life year (QALY) gained.

Results: Treatment with raloxifene improved clinical effectiveness by 0.006 QALY, with additional costs of USD 221 compared with conventional treatment. The incremental costeffectiveness ratio was USD 36,891 per QALY gained. The cost-effectiveness decision did not change in most of the one-way sensitivity analyses. With full raloxifene persistence and adherence, average effectiveness improved compared with the real-world scenario, and the incremental costeffectiveness ratio was USD 40,948 per QALY gained compared with conventional treatment. Conclusion: Given the willingness-to-pay threshold, raloxifene treatment was not cost-effective for treatment of osteoporotic fractures in postmenopausal Chinese women. Medication persistence and adherence had a great impact on clinical- and cost-effectiveness, and therefore should be incorporated in future pharmacoeconomic studies of osteoporosis interventions.
\end{abstract}

Keywords: cost-effectiveness, postmenopausal osteoporosis, Chinese, persistence, adherence

\section{Introduction}

In the People's Republic of China, osteoporosis affects approximately 30 million people older than 50 years of age. ${ }^{1,2}$ The majority of osteoporosis patients are postmenopausal women. ${ }^{2}$ The major outcomes of osteoporosis are fractures of the hip, vertebrae, and wrist, resulting in high hospital costs, reduced quality of life, and increased mortality. ${ }^{1,3-5}$ Chinese women are more prone to osteoporotic fractures than women 
in other populations, with approximately two in five Chinese women 50 years of age sustaining an osteoporotic fracture in their remaining lifetime compared with the worldwide average of one in three. ${ }^{6} \mathrm{With}$ a rapidly aging population, the combined economic and disease burden of osteoporosis and osteoporotic fractures on the Chinese health care system will increase substantially in future decades if no action is taken. ${ }^{7}$ Health policy makers need to identify the best ways to intervene to reduce the impact of this osteoporosis burden. Given the scarcity of health care resources, the decision-making process should include both clinical efficacy and economic considerations, and only those interventions that offer the best value for the money should be reimbursed.

Raloxifene is a selective estrogen receptor modulator with demonstrated clinical efficacy and plausible economic benefits in preventing osteoporotic fractures, and it has been selected as a first-line treatment for osteoporosis. ${ }^{8-10}$ In the People's Republic of China, patients treated with raloxifene are reimbursed up to $90 \%$ of the medication cost, but the strength of the economic evidence in support of reimbursement is unclear. ${ }^{10}$ The current medication reimbursement policy in the People's Republic of China is maintained by the Ministry of Labor and Social Security. Pharmaceuticals that are listed in the Basic Health Insurance Scheme (BHIS) formulary are fully or proportionally reimbursed. The number of medications listed on BHIS formulary ranged from more than 2,000 in 2004 to approximately 500 in the latest version that was released in 2013. ${ }^{11,12}$ The inclusion criteria of drugs in the BHIS formulary were not based on cost-effectiveness but at an attempt to provide basic drug coverage and to contain costs. As a consequence, this process has overlooked the comparison of health benefits from different treatments, ie, effectiveness. Cost-effectiveness analysis considers both costs and effectiveness and has been widely accepted in drug reimbursement submissions in many countries. ${ }^{13}$ However, the cost-effectiveness of the majority of medications that are listed in the BHIS formulary still remains unknown in the People's Republic of China.

The aim of this study was twofold. The first was to evaluate the cost-effectiveness of raloxifene compared with current osteoporosis treatment practices in the People's Republic of China, and the second was to assess the impact of medication persistence and adherence on the clinical- and cost-effectiveness of raloxifene.

\section{Research design and methods}

A modeling approach was used to evaluate the costeffectiveness of raloxifene compared with current osteoporosis treatment practices in postmenopausal women 65 years of age. The initial population comprised Chinese postmenopausal women 65 years of age with osteoporosis having a $T$-score of -2.5 or less at the femoral neck ${ }^{1}$ and without previous fractures. The evaluation was conducted from the Chinese health care payer's perspective and used a lifetime horizon simulation. The details and validation of this osteoporosis health economics model are described elsewhere. ${ }^{14}$ A brief description of the model is provided here.

\section{Health economics model}

The model was a state-transition microsimulation model comprising four disease states, namely, "no history of fractures",

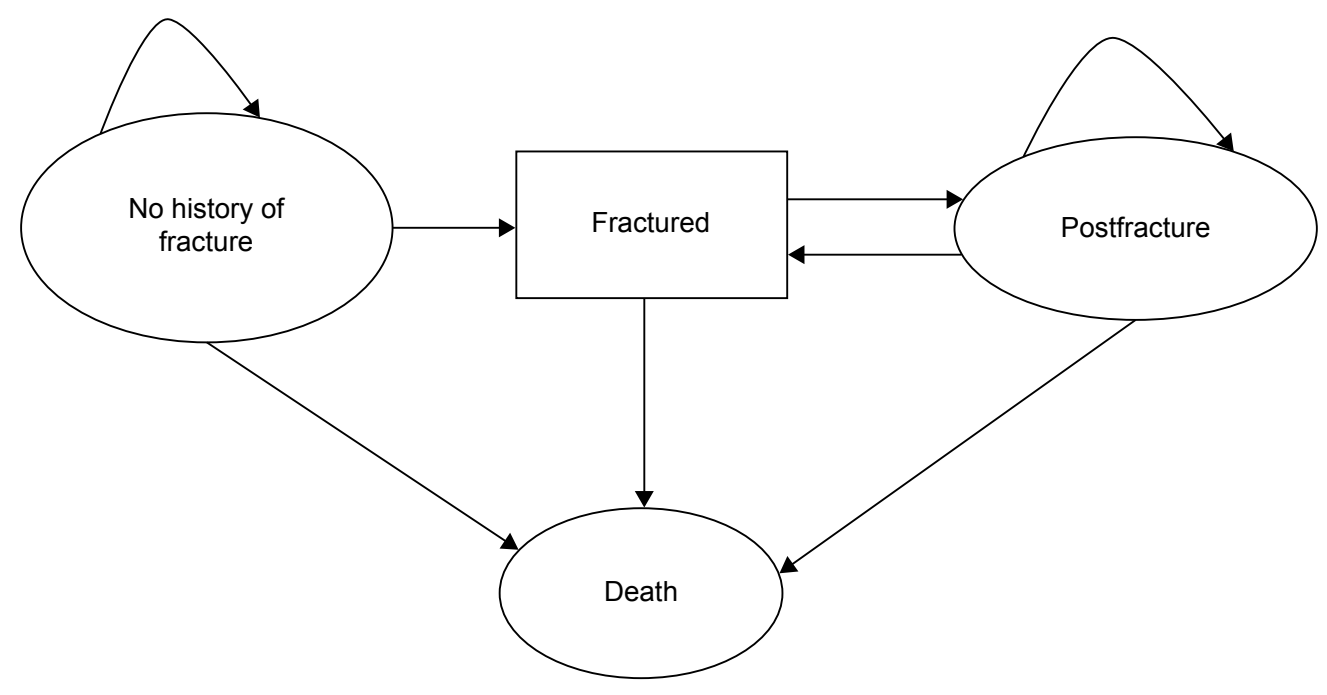

Figure I Structure of the osteoporosis state-transition model.

Notes: Simulated patients can transit between disease states in the direction shown by the arrow. "Fractured" is a temporary state and denotes patients with an existing osteoporotic hip, vertebral, or wrist fracture. All patients were simulated until "Death". Osteoporos Int. Screening for and treatment of osteoporosis: construction and validation of a state-transition microsimulation cost-effectiveness model. 26 (5) 2015:1477-I489. (C) International Osteoporosis Foundation and National Osteoporosis Foundation 2014. With permission of Springer. ${ }^{14}$ 
"fractured", "postfracture", and "death" (Figure 1). ${ }^{14}$ Hip, vertebral, and wrist fractures, which are known to be frequent osteoporotic fracture sites, were included in the "fractured" state. The simulated patients transited the model in 1-year cycles until they died. Tracker variables including "number of fractures", "type of fracture", "time after fracture treatment", and "time as a nursing home resident" were used to describe patient characteristics.

\section{Key model parameters}

The key parameters used in the health economics model are summarized in Table 1. Annual rates of hip and vertebral fractures were based on estimates in a Chinese population. ${ }^{15,16}$ Estimates of the annual rate of wrist fractures in the Chinese population were not available, therefore the model used data from an Asian population. ${ }^{17}$ Annual fracture rates were adjusted for attribution to osteoporosis as previously described by Melton et al, ${ }^{18}$ using age-specific osteoporosis prevalence rates in the Chinese population. ${ }^{2}$ Age-specific mortality rates for patients without any fractures were obtained from the China Public Health Statistical Yearbook $2012 .{ }^{19}$ We assumed an increased risk of morality for patients who experienced an osteoporotic fracture. ${ }^{3}$

Patients who have an osteoporotic fracture in the "conventional treatment" arm were assumed to receive medications to prevent subsequent fractures, and the choice of medication was based on current osteoporosis treatment practices in the

Table I Summary of key parameters in the health economics model

\begin{tabular}{|c|c|c|}
\hline Parameter & Model input & Distribution in PSA \\
\hline Prevalence of osteoporosis $(\%)^{2}$ & $\begin{array}{l}\text { I4.2 (60-69 years), } 26.8 \text { (70-79 years), } \\
39.2 \text { (80+ years) }\end{array}$ & - \\
\hline \multicolumn{3}{|l|}{ Fracture incidence (annual rate per I,000 person-years) } \\
\hline $\mathrm{Hip}^{15}$ & $\begin{array}{l}0.96 \text { (65-69 years), } 2.33 \text { ( } 70-74 \text { years), } \\
4.08 \text { (75-79 years), } 6.44 \text { ( } 80-84 \text { years), } \\
6.59 \text { ( } 85-89 \text { years), } 8.67 \text { ( } 90+\text { years) }\end{array}$ & - \\
\hline Clinical vertebral ${ }^{16}$ & $\begin{array}{l}5.64 \text { (65-69 years), } 8.74 \text { ( } 70-74 \text { years), } \\
12.05 \text { (75-79 years), } 21.19 \text { ( } 80-84 \text { years), } \\
26.89 \text { ( } 85-89 \text { years), } 27.10 \text { ( } 90+\text { years })\end{array}$ & - \\
\hline Wrist $^{17}$ & $\begin{array}{l}\text { I } 2.95 \text { (65-69 years), I } 3.17 \text { (70-74 years), } \\
\text { I } 3.87 \text { (75-79 years), I } 5.0 \text { I ( } 80-84 \text { years), } \\
\text { I } 5.10 \text { (85-89 years), I } 3.97 \text { ( } 90+\text { years })\end{array}$ & - \\
\hline Mortality rate $($ per 1,000$)$ for general population ${ }^{19}$ & $\begin{array}{l}\text { I0.3I (65-69 years), } 20.36 \text { (70-74 years), } \\
37.84 \text { (75-79 years), } 69.98 \text { ( } 80-84 \text { years), } \\
\text { I } 36.03 \text { ( } 85+\text { years })\end{array}$ & - \\
\hline SMR after a hip fracture ${ }^{3}$ & $2.43(95 \% \mathrm{Cl}=2.02-2.93)$ & Lognormal \\
\hline SMR after a clinical vertebral fracture ${ }^{3}$ & $\mathrm{I} .82(95 \% \mathrm{Cl}=\mathrm{I} .52-2.17)$ & Lognormal \\
\hline SMR after a wrist fracture ${ }^{3}$ & $\mathrm{I} .42(95 \% \mathrm{Cl}=\mathrm{I} .19-\mathrm{I} .70)$ & Lognormal \\
\hline \multicolumn{3}{|l|}{ Relative risk for fracture with alendronate treatment ${ }^{23}$} \\
\hline Primary prevention, nonvertebral & $0.89(95 \% \mathrm{Cl}=0.76-\mathrm{I} .04)$ & Lognormal \\
\hline Secondary prevention, nonvertebral & $0.77(95 \% \mathrm{Cl}=0.64-0.92)$ & Lognormal \\
\hline Primary prevention, vertebral & $0.55(95 \% \mathrm{Cl}=0.38-0.80)$ & Lognormal \\
\hline Secondary prevention, vertebral & $0.55(95 \% \mathrm{Cl}=0.43-0.69)$ & Lognormal \\
\hline $\begin{array}{l}\text { Relative risk for fracture with calcium combined with } \\
\text { vitamin } D \text { treatment }{ }^{2 !}\end{array}$ & $0.88(95 \% \mathrm{Cl}=0.78-0.99)$ & Lognormal \\
\hline \multicolumn{3}{|l|}{ Relative risk for fracture with calcitonin treatment ${ }^{22}$} \\
\hline Nonvertebral & $0.80(95 \% \mathrm{Cl}=0.59-1.09)$ & Lognormal \\
\hline Vertebral & $0.79(95 \% \mathrm{Cl}=0.62-\mathrm{I} .00)$ & Lognormal \\
\hline \multicolumn{3}{|l|}{ Relative risk for fracture with raloxifene treatment ${ }^{8}$} \\
\hline Non-vertebral & $0.92(95 \% \mathrm{Cl}=0.79-\mathrm{I} .07)$ & Lognormal \\
\hline Vertebral & $0.60(95 \% \mathrm{Cl}=0.50-0.70)$ & Lognormal \\
\hline \multicolumn{3}{|l|}{ Medication persistence ${ }^{29}$} \\
\hline Raloxifene & 0.502 (year I), 0.40I (year 2) & - \\
\hline Alendronate & $0.57 \mathrm{I}$ (year I), 0.4I8 (year 2) & - \\
\hline Calcitonin & 0.329 (year I), 0.235 (year 2) & - \\
\hline \multicolumn{3}{|l|}{ Medication adherence ${ }^{29, a}$} \\
\hline Raloxifene & 0.546 (year I), 0.437 (year 3) & - \\
\hline Alendronate & 0.619 (year I), 0.479 (year 3) & - \\
\hline Calcitonin & 0.364 (year I), 0.364 (year 3) & - \\
\hline
\end{tabular}


Table I (Continued)

\begin{tabular}{|c|c|c|}
\hline Parameter & Model input & Distribution in PSA \\
\hline \multicolumn{3}{|l|}{ Costs (20I5 USD) } \\
\hline Annual nursing home ${ }^{25}$ & 4,570 & - \\
\hline Hip fracture, inpatient ${ }^{5}$ & 6,720 & - \\
\hline Vertebral fracture, inpatient ${ }^{5}$ & 5,079 & - \\
\hline Wrist fracture, inpatient ${ }^{5}$ & 2,059 & - \\
\hline Alendronate, annual $\operatorname{cost}^{25}$ & $\mathrm{I}, 144$ & - \\
\hline Calcitonin, annual $\operatorname{cost}^{25}$ & 745 & - \\
\hline Raloxifene, annual $\operatorname{cost}^{25}$ & 1,056 & - \\
\hline Calcium combined with vitamin $\mathrm{D}$, annual cost ${ }^{25}$ & 93 & - \\
\hline \multirow[t]{3}{*}{ HSUVs for osteoporotic patients without fractures ${ }^{28}$} & 0.806 (65-69 years), 0.747 (70-74 years), & - \\
\hline & 0.73 I (75-79 years), 0.699 (80-84 years), & \\
\hline & $0.676(85+$ years $)$ & \\
\hline \multicolumn{3}{|l|}{ HSUV multipliers ${ }^{4, b}$} \\
\hline Hip fracture, first year & $0.776(95 \% \mathrm{Cl}=0.720-0.844)$ & Beta \\
\hline Hip fracture, subsequent years & $0.855(95 \% \mathrm{Cl}=0.800-0.909)$ & Beta \\
\hline Vertebral fracture, first year & $0.724(95 \% \mathrm{Cl}=0.667-0.779)$ & Beta \\
\hline Vertebral fracture, subsequent years & $0.868(95 \% \mathrm{Cl}=0.827-0.922)$ & Beta \\
\hline Wrist fracture, first year & $1.000(95 \% \mathrm{Cl}=0.960-1.000)$ & Triangular \\
\hline Wrist fracture, subsequent years & $1.000(95 \% \mathrm{Cl}=0.930-1.000)$ & Triangular \\
\hline \multicolumn{3}{|l|}{ Annual discount rates ${ }^{20}$} \\
\hline Costs & 0.03 & - \\
\hline Effectiveness & 0.03 & - \\
\hline
\end{tabular}

Notes: Medication adherence is measured by MPR; MPR $\geq 0.8$ was defined as high adherent. bMultipliers for the proportionate effects of fractures on HSUVs, calculated using data taken from Osteoporos Int. 2014;25(8):I-II. A systematic review and meta-analysis of utility-based quality of life for osteoporosis-related conditions. Si L, Winzenberg TM, de Graaff B, Palmer AJ, (C) International Osteoporosis Foundation and National Osteoporosis Foundation 20I4. With permission of Springer. ${ }^{4}$

Abbreviations: HSUV, health-state utility value; MPR, medication possession rate; PSA, probabilistic sensitivity analysis; SMR, standardized mortality ratio; USD, United States Dollars.

People's Republic of China. ${ }^{20}$ It has been reported that $51 \%$ of hospitalized patients with an osteoporotic fracture receive calcitonin and 29\% receive alendronate. We assumed that the remaining $20 \%$ of patients were given only calcium (600 $\mathrm{mg}$ per tablet) and vitamin $\mathrm{D}_{3}$ (125 international units per tablet) supplementation. ${ }^{5}$ In the "raloxifene treatment" arm, all patients with fractures were assumed to receive raloxifene $60 \mathrm{mg} / \mathrm{d}$ combined with calcium and vitamin D supplementation. The clinical effectiveness of medications indicated for prevention of osteoporotic fractures was obtained from meta-analyses that reported the highest evidence ranking hierarchy. ${ }^{8,20-23}$ We assumed a treatment duration of 5 years in the base case analysis, and the effects of this assumption was tested in sensitivity analyses.

We included only direct costs in this health care payer's perspective study. The treatment costs in the first year following a fracture were taken from a recent study in western China. ${ }^{5}$ All costs were converted to and presented in 2015 US dollars (USD) using an online costs converter. ${ }^{24}$ Annual costs of medication and nursing home residence were the government-recommended prices. ${ }^{25}$ Annual costs of medication were calculated from the daily cost, which was determined by the recommended retail price and recommended dosing. For example, a packet of $60 \mathrm{mg}$ raloxifene cost 84.6
Chinese Yuan (approximately USD 20.2) according to the government-recommended price. Given that one packet contains seven tablets and that patients are recommended to take one tablet per day, the daily cost of raloxifene was estimated at 12.1 Chinese Yuan (approximately USD 2.9). Annual cost of raloxifene was estimated at 4,411 Chinese Yuan (approximately USD 1,056).

Effectiveness was measured in quality-adjusted life years (QALYs). QALY is a generic measure of disease burden, incorporating both the quality and quantity of life lived. It is calculated by the cumulative health-state utility values (HSUVs) attached to the relevant years of life. ${ }^{26} \mathrm{HSUV}$ is a cardinal value that represents the quality-of-life weight, varying from 0 to 1 , where 0 equals death and 1 equals perfect health. ${ }^{27}$ There are direct or indirect methods to measure HSUV. Direct methods include the time trade-off, the standard gamble approach, and the visual analog approach, while indirect methods include the use of generic multiattribute utility instruments (EuroQoL 5 dimensions questionnaire [EQ-5D], Short Form 6D [SF-6D], the Health Utilities Index [HUI], and the Assessment of Quality of Life [AQoL]) or disease-specific preference measures. Age-specific HSUVs were measured using a visual analog approach in the 2008 Chinese National Health Services Survey. ${ }^{28}$ No HSUV 
loss was assumed for simulated patients without fractures. ${ }^{4}$ HSUVs for people with fractures were dependent on the fracture sites and time since the fracture events; the HSUV multipliers were retrieved from a recent meta-analysis of HSUVs for osteoporosis-related conditions. ${ }^{4,14}$ Both costs and effectiveness were discounted at 3\% annually in the base case analysis. ${ }^{20}$

\section{Medication persistence and adherence}

Poor medication adherence and persistence are common problems of osteoporosis management, ${ }^{29-31}$ and they affect the clinical- and cost-effectiveness of osteoporosis interventions. ${ }^{32}$ In this study, we used the International Society for Pharmacoeconomics and Outcomes Research definitions of medication adherence and persistence. ${ }^{33}$ Medication adherence (or compliance) is "the extent to which a patient acts in accordance with the prescribed interval and dose of a dosing regimen". ${ }^{33}$ The percentage of doses taken as prescribed, known as the medication possession ratio (MPR), was used to define the level of medication compliance, ${ }^{33}$ and an MPR of $\geq 80 \%$ was defined as high compliance. ${ }^{34}$ Medication persistence refers to "the duration of time from initiation to discontinuation of the therapy". ${ }^{33}$

For simulated patients who discontinued treatment, residual fracture reduction benefits were assumed to decline over 5 years in a linear manner. ${ }^{35}$ We assumed increases in fracture rate for patients with poor adherence, ${ }^{36,37}$ no medication cost for those who discontinued medication, and $80 \%$ of annual costs for poorly adherent patients. ${ }^{32}$

\section{Base case and sensitivity analyses}

Monte Carlo probabilistic sensitivity analyses (PSA) and microsimulations were conducted to address both stochastic and parameter uncertainties. ${ }^{38} \mathrm{~A}$ total of 1,000 sets of PSA were run, and in each of these simulations 1,000 patients were simulated. Average costs and effectiveness for each treatment strategy were aggregated from a total of 1 million $(1,000$ PSA $\times 1,000$ microsimulations) simulations. The incremental cost-effectiveness ratio (ICER) was calculated from the difference in average costs divided by the difference in average effectiveness of the raloxifene treatment and conventional treatment arms. We determined the cost-effectiveness decision using a willingness-to-pay (WTP) threshold of USD 20,000 per QALY gained, which is approximately three times the per capita gross domestic product in the People's Republic of China. ${ }^{20}$ In addition, we provided net monetary benefit (NMB) and net health benefit (NHB) estimates for the cost-effectiveness decision given the WTP threshold.
One-way sensitivity analyses were performed to evaluate the robustness of the ICER in response to changes of single parameter values in the model. In particular, the impact of medication persistence and adherence on cost-effectiveness of raloxifene were addressed in the one-way analyses.

All analyses were conducted using TreeAge Pro Suite 2015 (TreeAge Software, Williamstown, MA, USA). Presentation of the model and study results followed the Consolidated Health Economic Evaluation Reporting Standards (CHEERS) guidelines. ${ }^{39}$

\section{Results}

\section{Base case analysis}

Raloxifene treatment improved health outcomes at a higher cost than conventional treatment (Table 2). The average improvement of 0.006 in QALY and average incremental cost of USD 221 seen for raloxifene treatment resulted in an ICER of USD 36,891 per QALY gained. Given the current WTP threshold, raloxifene treatment had a $45 \%$ probability of being cost-effective (Figure 2). In addition, both NMB and NHB were negative.

\section{One-way sensitivity analyses}

In general, varying any of a number of critical parameter values within the model did not change the cost-effectiveness decision (Table 2). However, raloxifene treatment was costeffective given the current WTP threshold if the clinical efficacy was improved by $20 \%$ or the treatment duration was changed to 10 years.

\section{Impact of medication persistence and adherence on clinical- and cost- effectiveness of raloxifene}

High raloxifene persistence and adherence improved clinical effectiveness, but the costs were also higher (Table 3). It should be noted that the relative clinical effectiveness of conventional treatment increased if raloxifene persistence and adherence decreased more than $20 \%$. On the other hand, the average cost of raloxifene treatment was lower than that of conventional treatment if raloxifene persistence and adherence decreased more than $20 \%$. In addition, raloxifene treatment became costeffective compared with conventional treatment strategy if raloxifene persistence and adherence decreased by $30 \%-50 \%$.

\section{Discussion}

To our knowledge, this is the first study to evaluate the cost-effectiveness of raloxifene in the treatment of osteoporotic fractures in Chinese postmenopausal women using 
Table 2 Results of base case and one-way sensitivity analyses

\begin{tabular}{|c|c|c|c|c|c|c|c|c|c|}
\hline \multirow[t]{2}{*}{ Parameter } & \multicolumn{2}{|c|}{ Cost (20I5 USD) } & \multirow[t]{2}{*}{$\Delta C$} & \multicolumn{2}{|c|}{ Effectiveness (QALYs) } & \multirow[t]{2}{*}{$\Delta E$} & \multirow{2}{*}{$\begin{array}{l}\text { ICER (USD/ } \\
\text { QALY gained) }\end{array}$} & \multirow{2}{*}{$\begin{array}{l}\text { NHB }^{a} \\
\text { (QALYs) }\end{array}$} & \multirow{2}{*}{$\begin{array}{l}\text { NMB }^{a} \\
\text { (20I5 USD) }\end{array}$} \\
\hline & Conventional & Raloxifene & & Conventional & Raloxifene & & & & \\
\hline Base case & 5,114 & 5,336 & 221 & 8.7306 & 8.7366 & 0.0060 & 36,891 & -0.0051 & -101.34 \\
\hline Discount rate: 0 & 7,091 & 7,368 & 277 & $10.958 \mid$ & 10.9672 & 0.0091 & 30,445 & -0.0048 & -95.05 \\
\hline Discount rate: 0.05 & 4,255 & 4,448 & 193 & 7.6814 & 7.6860 & 0.0046 & 42,005 & -0.005 I & -101.22 \\
\hline $\begin{array}{l}\text { No residual effects after } \\
\text { medication discontinuation }\end{array}$ & 5,114 & 5,336 & 221 & 8.7139 & 8.7179 & 0.0040 & 55,336 & -0.007 I & -141.34 \\
\hline 0.8 times raloxifene efficacy & 5,114 & 5,336 & 221 & 8.7306 & 8.7302 & -0.0004 & $-553,360$ & -0.0115 & -229.34 \\
\hline I.2 times raloxifene efficacy & 5,114 & 5,336 & 221 & 8.7306 & 8.7472 & 0.0166 & 13,334 & 0.0055 & 110.66 \\
\hline 0.8 times raloxifene persistence & 5,114 & $5,|7|$ & 57 & 8.7202 & 8.7203 & 0.0001 & 565,640 & -0.0027 & -54.56 \\
\hline I.2 times raloxifene persistence & 5,114 & 5,567 & 453 & 8.7565 & 8.7724 & 0.0159 & 28,476 & -0.0067 & -134.76 \\
\hline 0.8 times raloxifene adherence & 5,114 & 5,326 & 211 & 8.7306 & 8.7315 & 0.0009 & $234,85 I$ & -0.0097 & -193.37 \\
\hline I.2 times raloxifene adherence & 5,114 & 5,346 & 231 & 8.7306 & 8.7426 & 0.0120 & 19,268 & 0.0004 & 8.79 \\
\hline Treatment duration: 2 years & 4,926 & 4,958 & 32 & 8.7306 & 8.7361 & 0.0055 & 5,805 & 0.0039 & 78.07 \\
\hline Treatment duration: 10 years & 4,926 & 4,958 & 32 & 8.7306 & 8.7373 & 0.0067 & 4,765 & 0.0051 & 102.07 \\
\hline 0.8 times annual fracture rates & 4,157 & 4,343 & 186 & 9.0458 & 9.0497 & 0.0039 & 47,677 & -0.0054 & -107.94 \\
\hline 1.2 times annual fracture rates & 6,051 & 6,309 & 258 & 8.4288 & 8.4365 & 0.0077 & 33,452 & -0.0052 & -103.58 \\
\hline 0.8 times fracture inpatient costs & 4,286 & 4,512 & 226 & 8.7306 & 8.7366 & 0.0060 & 37,730 & -0.0053 & -106.38 \\
\hline I.2 times fracture inpatient costs & 5,943 & 6,159 & 216 & 8.7306 & 8.7366 & 0.0060 & 36,051 & -0.0048 & -96.31 \\
\hline 0.8 times nursing home costs & 4,972 & 5,192 & 221 & 8.7306 & 8.7366 & 0.0060 & 36,756 & -0.0050 & -100.54 \\
\hline I.2 times nursing home costs & 5,257 & 5,479 & 222 & 8.7306 & 8.7366 & 0.0060 & 37,025 & -0.0051 & -102.15 \\
\hline 0.8 times annual raloxifene costs & 5,114 & 5,235 & $12 \mid$ & 8.7306 & 8.7366 & 0.0060 & 20,193 & -0.0001 & -1.16 \\
\hline 1.2 times annual raloxifene costs & 5,114 & 5,436 & 322 & 8.7306 & 8.7366 & 0.0060 & 53,588 & -0.0101 & -201.53 \\
\hline 0.8 times base case HSUV & 5,114 & 5,336 & 221 & 6.8554 & 6.8607 & 0.0053 & 41,763 & -0.0058 & -115.34 \\
\hline 1.2 times base case HSUV & 5,114 & 5,336 & 221 & 10.6890 & 10.6953 & 0.0063 & 35,134 & -0.0048 & -95.34 \\
\hline Initial population age: 70 years & $4,5 \mid 4$ & 4,686 & 173 & 7.1923 & 7.1981 & 0.0058 & 29,768 & -0.0028 & -56.65 \\
\hline Initial population age: 75 years & 3,870 & 4,006 & 136 & 5.6785 & 5.6832 & 0.0047 & 28,958 & -0.0021 & -42.10 \\
\hline Initial population age: 80 years & 3,159 & 3,272 & 113 & 4.3061 & 4.3110 & 0.0049 & 23,084 & -0.0008 & -15.11 \\
\hline
\end{tabular}

Note: aWillingness-to-pay threshold is set at USD 20,000 per QALY gained.

Abbreviations: USD, United States Dollars; QALY, quality-adjusted life year; ICER, incremental cost-effectiveness ratio; $\Delta C$, incremental costs; $\Delta E$, incremental effectiveness; NHB, net health benefit; NMB, net monetary benefit; HSUV, health-state utility value.

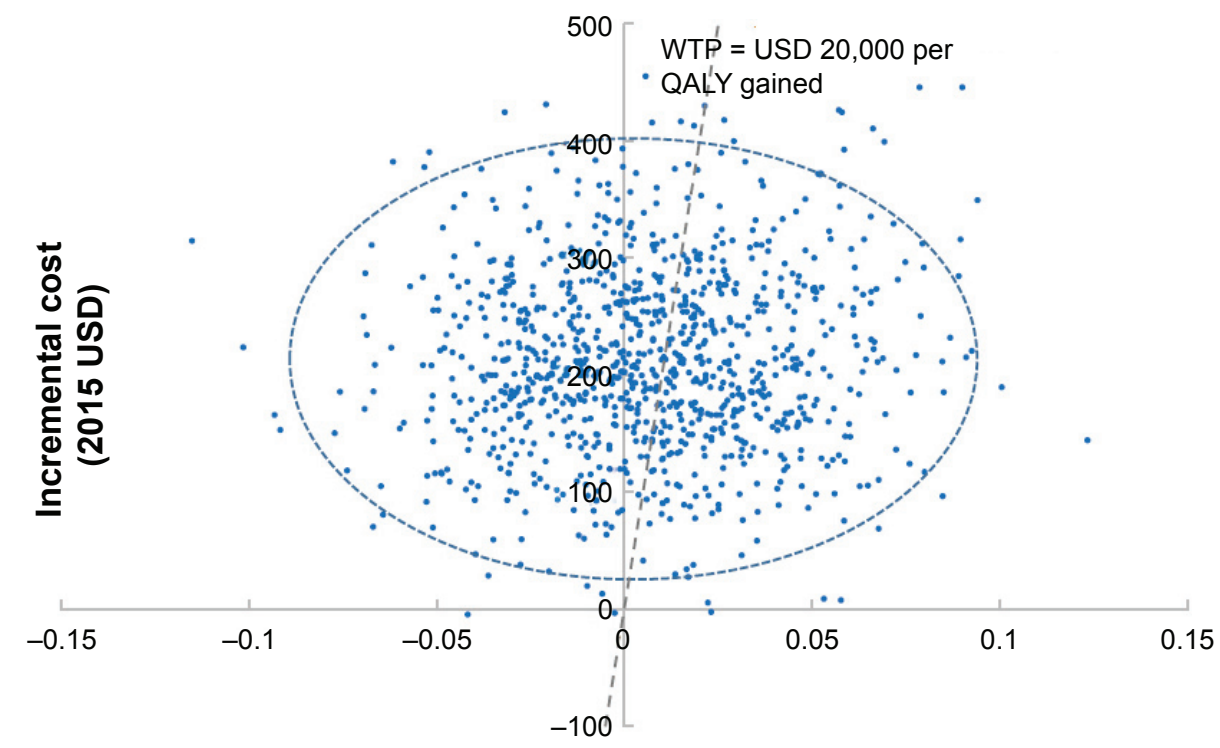

\section{Incremental effectiveness (QALYs)}

Figure 2 Scatter plot of estimated joint density of incremental cost (2015 USD) and incremental effectiveness (QALYs) of raloxifene versus conventional treatment obtained from probabilistic sensitivity analyses.

Notes: Mean incremental cost is USD 221 and mean incremental effectiveness is 0.006 QALYs for raloxifene versus conventional treatment. Dotted line denotes the WTP threshold, the plots to the right of the WTP threshold are cost-effective. Given a WTP threshold of USD 20,000 per QALY gained, treatment with raloxifene has a 45\% probability of being cost-effective.

Abbreviations: QALY, quality-adjusted life year; WTP, willingness-to-pay; USD, United States Dollars. 
Table 3 One-way sensitivity analyses of the impact of raloxifene persistence and adherence on clinical- and cost-effectiveness

\begin{tabular}{|c|c|c|c|c|c|c|c|c|c|}
\hline \multirow{2}{*}{$\begin{array}{l}\text { Raloxifene persistence and } \\
\text { adherence multipliers }\end{array}$} & \multicolumn{2}{|c|}{ Cost (20I5 USD) } & \multirow[t]{2}{*}{$\Delta C$} & \multicolumn{2}{|c|}{ Effectiveness (QALYs) } & \multirow[t]{2}{*}{$\Delta E$} & \multirow{2}{*}{$\begin{array}{l}\text { ICER (USDI } \\
\text { QALY gained) }\end{array}$} & \multirow[t]{2}{*}{$\mathrm{NHB}^{a}$} & \multirow[t]{2}{*}{ NMB $^{a}$} \\
\hline & Conventional & Raloxifene & & Conventional & Raloxifene & & & & \\
\hline 0.5 times base case value & 5,114 & 5,005 & -109 & 8.7306 & 8.7252 & -0.0054 & 20,233 & -0.011 & 1.26 \\
\hline 0.6 times base case value & 5,114 & 5,047 & -68 & 8.7306 & 8.7268 & -0.0038 & 17,833 & -0.007 & -8.23 \\
\hline 0.7 times base case value & 5,114 & 5,100 & -14 & 8.7306 & 8.7292 & -0.0014 & 10,356 & -0.002 & -13.50 \\
\hline 0.8 times base case value & 5,114 & 5,164 & 50 & 8.7306 & 8.7311 & 0.0005 & 99,978 & 0.003 & -39.99 \\
\hline 0.9 times base case value & 5,114 & 5,242 & 128 & 8.7306 & 8.7338 & 0.0032 & 39,940 & 0.010 & -63.81 \\
\hline Base case & 5,114 & 5,336 & 221 & 8.7306 & 8.7366 & 0.0060 & 36,891 & 0.017 & -101.34 \\
\hline I.I times base case value & 5,114 & 5,448 & 334 & 8.7306 & 8.7398 & 0.0092 & 36,296 & 0.026 & -149.92 \\
\hline I.2 times base case value & 5,114 & 5,582 & 468 & 8.7306 & 8.7435 & 0.0129 & 36,245 & 0.036 & -209.56 \\
\hline I. 3 times base case value & 5,114 & 5,738 & 624 & 8.7306 & 8.7478 & 0.0172 & 36,282 & 0.048 & -280.06 \\
\hline I. 4 times base case value & 5,114 & 5,918 & 804 & 8.7306 & 8.7531 & 0.0225 & 35,716 & 0.063 & -353.61 \\
\hline I.5 times base case value & 5,114 & 6,122 & 1,008 & 8.7306 & 8.7593 & 0.0287 & 35,107 & 0.079 & -433.56 \\
\hline Full persistence and adherence & 5,114 & 8,128 & 3,014 & 8.7306 & 8.8042 & 0.0736 & 40,948 & $-0.077 \mid$ & $-|, 54| .74$ \\
\hline
\end{tabular}

Note: ${ }^{a}$ Willingness-to-pay threshold is set at USD 20,000 per QALY gained.

Abbreviations: USD, United States Dollars; $\Delta C$, incremental costs; $\triangle E$, incremental effectiveness; QALY, quality-adjusted life year; ICER, incremental cost-effectiveness ratio; NHB, net health benefit; NMB, net monetary benefit; HSUV, health-state utility value.

a modeling approach. ${ }^{14,40}$ In addition, we assessed the impact of raloxifene persistence and adherence on clinical- and cost-effectiveness. Compared with conventional treatment, the overall clinical effectiveness was improved by raloxifene, but the cost was increased. Given the current WTP threshold, raloxifene was not cost-effective compared with the conventional treatment given in the People's Republic of China to postmenopausal women with osteoporotic fractures. Although clinical effectiveness was improved with increases in raloxifene persistence and adherence, the costeffectiveness decision did not change.

The effect of medication persistence and adherence on cost-effectiveness was twofold. First, high persistence and adherence affected average costs. In this study, average costs in the raloxifene treatment arm increased by $52 \%$ with full persistence and adherence compared with that in the base case (Table 3). Second, high persistence and adherence increased clinical effectiveness, but the improvement was marginal in this study. The average effectiveness with full raloxifene persistence and adherence was 8.8042 QALYs, which was $0.0676(0.7 \%)$ greater than in the base case. As medication persistence and adherence affected both cost and clinical outcomes, its impact on cost-effectiveness was case based.

Our results confirmed that it is important to incorporate medication persistence and adherence in health economic evaluation studies, a finding that is significant not only in the context of osteoporosis but also in other disease areas. ${ }^{41,42}$ Given the differences in disease profiles, socioeconomic status, and pharmacoeconomic guidelines, health economics studies in different jurisdictions and populations are encouraged, and the impact of medication persistence and adherence on cost-effectiveness would be expected to vary in different countries. Therefore, the application of our results to other jurisdictions needs scrutiny. In a Belgian study evaluating the clinical and economic burden of nonadherence to oral bisphosphonates, the ICER was Euro 10,279 (USD 11,472) with full adherence, and Euro 3,909 (USD 4,363) with "realworld" (ie, actual) adherence compared with no treatment. ${ }^{41}$ In our analysis, we observed a higher ICER (USD 40,948 vs USD 36,891 per QALY gained) with full raloxifene persistence and adherence compared with that with real-world persistence and adherence. The primary reason for this difference was that the ratio of fracture inpatient costs to raloxifene cost in the Chinese population was substantially smaller than that in the Belgian study population. ${ }^{5,41}$ Inpatient costs in the People's Republic of China for hip, vertebral, and wrist fractures were USD 6,720, USD 5,079, and USD 2,059 , respectively, and the annual raloxifene cost was USD $1,149 ., 25$ Consequently, the cost of raloxifene outstripped the decrease in the cost of treating fractures, resulting in higher average costs and ICER with full medication persistence and adherence compared with the real-world scenario (Tables 1 and 3).

In line with the Chinese Guidelines for Pharmacoeconomic Evaluations, the current treatment pattern was used in our study as the comparator. ${ }^{20}$ Given that more than half of hospitalized patients with fractures received calcitonin to prevent subsequent fractures, the cost-effectiveness of raloxifene in the People's Republic of China might differ from those that used other comparators - for example, no treatment. ${ }^{9}$ Both the current practice and no-treatment are commonly used comparators in health economic evaluations. ${ }^{26}$ 
However, no-treatment was not an appropriate comparator in our study, because evidence has shown that osteoporotic patients with fragility fractures are more likely to have subsequent fractures; therefore, in practice, they are prescribed with medications to prevent subsequent fractures. ${ }^{43}$

Our study has several limitations that should be addressed. First, health effects such as coronary heart disease, breast cancer, venous thromboembolism, and fatal stroke that might have been associated with raloxifene treatment were not included in our analyses. ${ }^{44}$ Although evidence has shown the benefits of raloxifene in reducing the risks of invasive breast cancer; the objective of this study was to evaluate the cost-effectiveness of raloxifene in treatment of osteoporotic fractures. Second, we included only hip, vertebral, and wrist fractures in the model because of the paucity of Chinese data on fractures at other sites such as the proximal humerus, pelvis, distal femur, and proximal tibia, which are also associated with low bone density. ${ }^{45}$ In addition, because of limited data on relative risks of mortality after an osteoporotic fracture, treatment efficacy, and health utility values for postfracture status in the Chinese population, such values were taken from other populations. An updated study should be conducted when such data are available in the Chinese population. Finally, large variations in fracture risks have been shown to exist in different populations within a country. ${ }^{46}$ Given that we have used regional hip and clinical vertebral fracture rates, our results might not be representative of the whole county.

\section{Conclusion}

Given the current fracture treatment practices, inpatient costs, medication costs, and WTP threshold in the People's Republic of China, raloxifene is not cost-effective compared with the current management of osteoporotic fractures. Medication persistence and adherence have a strong impact on both clinical- and cost-effectiveness, and therefore should be incorporated in pharmacoeconomic studies.

\section{Acknowledgments}

This work was supported by the National Natural Science Foundation of China (grant number: 71503007) and Jiangsu Research on Philosophy \& Social Science in University of Education Department of Jiangsu Province (grant number: 2014SJB157). The views expressed are those of the researchers and do not necessarily reflect those of the funding bodies.

\section{Disclosure}

The authors report no conflicts of interest in this work.

\section{References}

1. Kanis JA. Diagnosis of osteoporosis and assessment of fracture risk. Lancet. 2002;359(9321):1929-1936.

2. Zhang ZQ, Ho SC, Chen ZQ, Zhang CX, Chen YM. Reference values of bone mineral density and prevalence of osteoporosis in Chinese adults. Osteoporos Int. 2014;25(2):497-507.

3. Bliuc D, Nguyen ND, Milch VE, Nguyen TV, Eisman JA, Center JR. Mortality risk associated with low-trauma osteoporotic fracture and subsequent fracture in men and women. JAMA. 2009;301(5):513-521.

4. Si L, Winzenberg TM, de Graaff B, Palmer AJ. A systematic review and meta-analysis of utility-based quality of life for osteoporosis-related conditions. Osteoporos Int. 2014;25(8):1-11.

5. Qu B, Ma Y, Yan M, et al. The economic burden of fracture patients with osteoporosis in western China. Osteoporos Int. 2014;25(7):1853-1860.

6. Si L, Winzenberg TM, Chen M, Jiang Q, Palmer AJ. Residual lifetime and 10 year absolute risks of osteoporotic fractures in Chinese men and women. Curr Med Res Opin. 2015;31(6):1149-1156.

7. Si L, Winzenberg TM, Jiang Q, Chen M, Palmer AJ. Projection of osteoporosis-related fractures and costs in China: 2010-2050. Osteoporos Int. 2015;26(7):1929-1937.

8. Cranney A, Tugwell P, Zytaruk N, et al. Meta-analyses of therapies for postmenopausal osteoporosis. IV. Meta-analysis of raloxifene for the prevention and treatment of postmenopausal osteoporosis. Endocr Rev. 2002;23(4):524-528

9. Borgstrom F, Johnell O, Kanis JA, Oden A, Sykes D, Jonsson B. Cost effectiveness of raloxifene in the treatment of osteoporosis in Sweden: an economic evaluation based on the MORE study. Pharmacoeconomics. 2004;22(17):1153-1165.

10. Mithal A, Ebeling P, Kyer CS. Asia-Pacific regional audit: epidemiology, costs and burden of osteoporosis in 2013. Nyon, Switzerland: International Osteoporosis Foundation; 2013.

11. Ministry of Labor and Social Security of the People's Republic of China. Notice about publishing BHIS Formulary. 2004. Chinese.

12. Ministry of Labor and Social Security of the People's Republic of China. Notice about publishing BHIS Formulary. 2013. Chinese.

13. Clement FM, Harris A, Li J, Yong K, Lee KM, Manns BJ. Using effectiveness and cost-effectiveness to make drug coverage decisions: a comparison of Britain, Australia, and Canada. JAMA. 2009; 302(13):1437-1443.

14. Si L, Winzenberg TM, Jiang Q, Palmer AJ. Screening for and treatment of osteoporosis: construction and validation of a state-transition microsimulation cost-effectiveness model. Osteoporos Int. 2015; 26(5):1477-1489.

15. Wang J, Wang Y, Liu WD, Wang F, Yin ZS. Hip fractures in Hefei, China: the Hefei osteoporosis project. J Bone Miner Metab. 2014;32(2): 206-214.

16. Bow $\mathrm{CH}$, Cheung E, Cheung CL, et al. Ethnic difference of clinical vertebral fracture risk. Osteoporos Int. 2012;23(3):879-885.

17. Lofthus CM, Frihagen F, Meyer HE, Nordsletten L, Melhuus K, Falch JA. Epidemiology of distal forearm fractures in Oslo, Norway. Osteoporos Int. 2008;19(6):781-786.

18. Melton LJ 3rd, Thamer M, Ray NF, et al. Fractures attributable to osteoporosis: report from the National Osteoporosis Foundation. J Bone Miner Res. 1997;12(1):16-23.

19. Ministry of Health of the People's Republic of China. China Public Health Statistical Yearbook. Beijing, China: Peking Union Medical College Publishing House; 2012.

20. China Center for Health Economic Research. China Guidelines for Pharmacoeconomic Evaluations. Beijing, China: China Center for Health Economic Research; 2011.

21. Chung M, Lee J, Terasawa T, Lau J, Trikalinos TA. Vitamin D with or without calcium supplementation for prevention of cancer and fractures: an updated meta-analysis for the U.S. Preventive Services Task Force. Ann Intern Med. 2011;155(12):827-838.

22. Cranney A, Tugwell P, Zytaruk N, et al. Meta-analyses of therapies for postmenopausal osteoporosis. VI. Meta-analysis of calcitonin for the treatment of postmenopausal osteoporosis. Endocr Rev. 2002;23(4):540-551. 
23. Wells GA, Cranney A, Peterson J, et al. Alendronate for the primary and secondary prevention of osteoporotic fractures in postmenopausal women. Cochrane Database Syst Rev. 2008;(1):Cd001155.

24. CCEMG, EPPI. CCEMG - EPPI-Centre Cost Converter. 2013. Available from: http://eppi.ioe.ac.uk/costconversion/default.aspx. Accessed April 24, 2013.

25. Medicine Price Platform, Jiangsu Province. Available from: http:// yy.jspn.net/. Accessed July 4, 2014.

26. Gray AM, Clarke PM, Wolstenholme JL, Wordsworth S. Applied Methods of Cost-Effectiveness Analysis in Healthcare. Oxford, UK: Oxford University Press; 2010:88-89.

27. Tolley K. What are Health Utilities. London, UK: Hayward Medical Communications; 2009:1-8.

28. Sun S, Chen J, Johannesson M, et al. Population health status in China: EQ-5D results, by age, sex and socio-economic status, from the National Health Services Survey 2008. Qual Life Res. 2011;20(3):309-320.

29. Cheng TT, Yu SF, Hsu CY, Chen SH, Su BY, Yang TS. Differences in adherence to osteoporosis regimens: a 2-year analysis of a population treated under specific guidelines. Clin Ther. 2013;35(7): 1005-1015.

30. Giusti A, Barone A, Razzano M, et al. Persistence with calcium and vitamin D in elderly patients after hip fracture. J Bone Miner Metab. 2009;27(1):95-100.

31. Jackson RD, LaCroix AZ, Gass M, et al. Calcium plus vitamin D supplementation and the risk of fractures. N Engl J Med. 2006;354(7): 669-683.

32. Hiligsmann M, Boonen A, Rabenda V, Reginster JY. The importance of integrating medication adherence into pharmacoeconomic analyses: the example of osteoporosis. Expert Rev Pharmacoecon Outcomes Res. 2012;12(2):159-166.

33. Cramer JA, Roy A, Burrell A, et al. Medication compliance and persistence: terminology and definitions. Value Health. 2008;11(1):44-47.

34. Siris ES, Selby PL, Saag KG, Borgstrom F, Herings RM, Silverman SL. Impact of osteoporosis treatment adherence on fracture rates in North America and Europe. Am J Med. 2009;122(2 Suppl):S3-S13.

35. Nayak S, Roberts MS, Greenspan SL. Cost-effectiveness of different screening strategies for osteoporosis in postmenopausal women. Ann Intern Med. 2011;155(11):751-761.
36. Huybrechts KF, Ishak KJ, Caro JJ. Assessment of compliance with osteoporosis treatment and its consequences in a managed care population. Bone. 2006;38(6):922-928.

37. Rabenda V, Mertens R, Fabri V, et al. Adherence to bisphosphonates therapy and hip fracture risk in osteoporotic women. Osteoporos Int. 2008;19(6):811-818.

38. Briggs AH, Weinstein MC, Fenwick EA, Karnon J, Sculpher MJ, Paltiel AD. Model parameter estimation and uncertainty: a report of the ISPOR-SMDM modeling good research practices task force -6 . Value Health. 2012;15(6):835-842.

39. Husereau D, Drummond M, Petrou S, et al. Consolidated health economic evaluation reporting standards (CHEERS) - explanation and elaboration: a report of the ISPOR health economic evaluation publication guidelines good reporting practices task force. Value Health. 2013;16(2):231-250.

40. Si L, Winzenberg TM, Palmer AJ. A systematic review of models used in cost-effectiveness analyses of preventing osteoporotic fractures. Osteoporos Int. 2014;25(1):51-60.

41. Hiligsmann M, Rabenda V, Bruyere O, Reginster JY. The clinical and economic burden of non-adherence with oral bisphosphonates in osteoporotic patients. Health Policy. 2010;96(2):170-177.

42. Cobden DS, Niessen LW, Rutten FFH, Redekop WK. Modeling the economic impact of medication adherence in type 2 diabetes: a theoretical approach. Patient Prefer Adherence. 2010;4:283-290.

43. Bliuc D, Alarkawi D, Nguyen TV, Eisman JA, Center JR. Risk of subsequent fractures and mortality in elderly women and men with fragility fractures with and without osteoporotic bone density: the Dubbo Osteoporosis Epidemiology Study. J Bone Miner Res. 2015;30(4): 637-646.

44. Barrett-Connor E, Mosca L, Collins P, et al. Effects of raloxifene on cardiovascular events and breast cancer in postmenopausal women. N Engl J Med. 2006;355(2):125-137.

45. Cummings SR, Melton LJ. Epidemiology and outcomes of osteoporotic fractures. Lancet. 2002;359(9319):1761-1767.

46. Cooley H, Jones G. A population-based study of fracture incidence in southern Tasmania: lifetime fracture risk and evidence for geographic variations within the same country. Osteoporos Int. 2001;12(2): 124-130.
Patient Preference and Adherence

\section{Publish your work in this journal}

Patient Preference and Adherence is an international, peer-reviewed, open access journal that focuses on the growing importance of patient preference and adherence throughout the therapeutic continuum. Patient satisfaction, acceptability, quality of life, compliance, persistence and their role in developing new therapeutic modalities and compounds to optimize

\section{Dovepress}

clinical outcomes for existing disease states are major areas of interest for the journal. This journal has been accepted for indexing on PubMed Central. The manuscript management system is completely online and includes a very quick and fair peer-review system, which is all easy to use. Visit http://www. dovepress.com/testimonials.php to read real quotes from published authors. 